\title{
Relações de poder na vida conjugal e prevenção da AIDS
}

\author{
Power relationships in marriage and the prevention of AIDS
}

Relaciones de poder en el matrinonio y prevención del SIDA

\section{Valéria Silvana Faganello Madureira', Mercedes Trentini' \\ 'Universidade do Contestado. Concórdia, SC}

\author{
Submissão: 07/04/2008
}

Aprovação: 15/09/2008

\section{RESUMO}

Este ensaio tem o objetivo de discutir as interfaces existentes entre a prevenção da AIDS e as relações afetivo-sexuais e de poder na vida conjugal. O tema é interpretado à luz do referencial foucaultiano de poder e emergiu de uma pesQuisa conduzida anteriormente. $\mathrm{O}$ pacto de fidelidade, assumido pelo homem como compromisso consigo próprio e com a mulher, contribui para Que considere remota a hipótese de contaminação sexual. Entretanto, mesmo distante, a possibilidade de contrair aids provoca certa insegurança no homem, Que se sente dependente do comportamento da parceira nessa Questão.

Descritores: Relações conjugais; Síndrome de Imunodeficiência AdQuirida/prevenção \& controle; Gênero e saúde.

ABSTRACT
This paper's object is to discuss the interfaces between the prevention of AIDS and affective-sexual relationships and power in marriage. The subject matter is interpreted in light of the foucaultian thinking of power, and emerged from previous research. The fidelity pact assumed by the man as a commitment to himself and to his wife, contributes to the consideration that the hypothesis of sexual contamination is remote. However, even though distant, the possibility of contracting aids provokes a certain insecurity in the man, who feels dependent on his partner's behavior with regard to this issue.

Descriptors: Marriage; Aceuired Immunodeficiency Syndrome/prevention \& control; Gender and health.

\section{RESUMEN}

Este artículo tiene el objetivo de discutir las interconexiones existentes entre la prevención del SIDA y las relaciones afectivo/sexuales y de poder en la vida conyugal. El tema es interpretado frente a la referencia concerniente al poder según Foucault y surgió de un estudio conducido anteriormente. El pacto de fidelidad, tomado por el hombre como compromiso consigo mismo y con la mujer, contribuye para que considere remota la hipótesis de contaminación sexual. Sin embargo, aún distante, la posibilidad de contraer el SIDA provoca cierta inseguridad en el hombre, Que se siente dependiente del comportamiento de la compañera en esta cuestión.

Descriptores: Matrimonio; Síndrome de Inmunodeficiencia AdQuirida/prevención \& controle; Género y salud. 


\section{INTRODUÇÃO}

O poder é visto de forma positiva, com ênfase em sua força produtiva, Que tem a produção do sujeito como um de seus principais resultados. Assim, o poder só se exerce em relação, se situa na vida cotidiana de cada um e é imanente a todas as relações. Isso confere outras nuanças às relações, inclusive àQuelas sempre pensadas em termos de dominação, com um dos sujeitos colocado na posição de vítima, de submissão. Um exemplo disso é a representação das relações homem-mulher, na Qual a mulher é geralmente considerada o pólo sobre o Qual incide o poder do homem $^{(1,2)}$.

As relações de poder podem ser comparadas a uma teia Que se expande por todo o corpo social. No interior dela se dão as lutas pela inversão de posições o Que retira do poder as polaridades segundo as Quais alguém manteria todo o poder em suas mãos, eneuanto outros, sem nada de poder, se submeteriam. As relações de poder implicam força desigual e relativamente estabilizada, o Que remete à existência simultânea de um movimento de cima para baixo e de uma capilaridade de baixo para cima, Que as sustenta dando a idéia de dois pratos de uma balança que se equilibram tendo sempre a possibilidade de inverter posições.

Nas relações de casal, a conjugalidade heterossexual é estabelecida como normal, o Que pressupõe um ideal de homem, um ideal de mulher, um ideal de relação, com papéis e lugares feminino e masculino dados de antemão, de acordo com o Que é socioculturalmente construído e aceito como normal. Aqui se revela a generificação das relações de poder, em referência ao processo social, histórico e cultural de construção do ser homem e do ser mulher, da masculinidade e da feminilidade. Assim falando, gênero focaliza as significações sociais e simbólicas relacionadas a um deverser para homens e mulheres. As assimetrias nas relações homemmulher abrem o espaço ideal para o exercício do poder e, na conjugalidade heterossexual, nos provocam a considerar o jogo de poder no seio dessa relação, a Qual geralmente se constitui sobre o pano de fundo das polaridades de gênero. Outro elemento a considerar é a dupla moral sexual Que vigora para homens e mulheres, de acordo com a Qual espera-se da mulher um comportamento mais contido, reservado, com um único parceiro eneuanto, para os homens, as expectativas são menos restritivas, com um comportamento sexual mais ativo, mais agressivo.

A AIDS se inscreve no âmbito da sexualidade e vem carregada de preconceito, não estando de acordo com o 'perfil ideal' de homem e de mulher socialmente construído. Hoje, está intensamente presente nas relações heterossexuais estáveis, nas Quais as relações de gênero são marcadas pela dupla moral sexual e por assimetrias de posições entre as Quais o poder circula. As assimetrias nas relações entre os gêneros e a sexualidade masculina e feminina contribuem para dificultar a negociação das trocas estabelecidas entre o casal. Essas dificuldades se manifestam nas iniciativas de prevenção baseadas principalmente na noção de sexo mais seguro, o Que implica o uso do preservativo masculino, muito mais controlado pelo homem do Que pela mulher e cujo uso depende da cooperação mútua entre os parceiros. Em relacionamentos estáveis, falar de práticas sexuais seguras e do uso de preservativo pode ameaçar a confiança entre o casal, expondo a possibilidade de relações extraconjugais e Questionando a fidelidade.
As relações de poder, as relações de gênero e o crescimento da aids por transmissão heterossexual voltam o foco do biopoder e da disciplina para as relações homem-mulher. Esta constatação incentivou-nos a elaborar o presente ensaio com o objetivo de discutir as relações afetivo-sexuais, enfatizando as interfaces existentes entre as relações de poder na vida conjugal e a prevenção de aids, tema este gerado na Tese de Doutorado de Madureira ${ }^{(3)}$.

\section{RELAÇÕES AFETIVO-SEXUAIS}

A sexualidade é um campo no Qual o biopoder se exerce de forma privilegiada, justamente por reunir um aspecto individual, de comportamento a ser controlado, vigiado e disciplinado, vinculado a outro, relacionado à procriação, Que se insere em processos mais amplos relativos à população. Isso a coloca no limiar do corpo e da população, sujeita a mecanismos disciplinares e regulamentadores articulados entre si. No Que se refere ao biopoder e no limiar em Que se encontra a sexualidade, trava-se uma luta contínua entre o coletivo e o individual na Qual o primeiro tenta disciplinar o segundo que, por sua vez, inscreve-se no âmbito íntimo, onde as práticas dão novas dimensões ao dito, ao não dito, ao interdito, às transgressões, às proibições.

As medidas de controle da aids reforçam o saber-poder, desencadeando medidas Que têm pelo menos duas faces: uma, Que se volta para a prevenção da propagação da doença; outra, Que se imiscui na vida dos indivíduos para extrair a verdade sobre eles e sobre suas condutas. Pode-se então imaginar uma teia cujos fios se estendem em todas as direções, Que delineia o campo no Qual são travadas as lutas para o controle da epidemia, diagnóstico e tratamento dos portadores e doentes, para a manutenção Quantitativa e Qualitativa da vida e na Qual o discurso científico produz normas, regras e regulamentações.

Os elementos 'amor, desejo, prazer e fidelidade', definidos e aceitos como verdadeiros em uma relação conjugal, delineiam uma maneira de viver em casal construída pelos parceiros, Que podem interpretar a vinculação existente entre estes elementos de forma estrita ou relativa.

Uma interpretação estrita considera amor, desejo, prazer e fidelidade intimamente ligados e interdependentes. Essa forma de interpretar vincula o viver em casal com o próprio homem e com a busca constante Que ele empreende para alcançar um ideal de homem.

A constituição como homem solicita um trabalho sobre si mesmo para alcançar soberania sobre si, no Que está incluído o campo afetivo-sexual do viver e os elementos do processo de tornar-se homem Que ele engloba (vida sexual, casamento, família e filhos). Este campo é regulado por códigos de conduta Que balizam os limites dentro dos Quais o homem pode viver seus afetos e sua sexualidade.

Há, aQui, uma convergência entre o vivido contemporaneamente por esses homens e a noção de enkrateia presente na problematização moral da atividade sexual entre os gregos ${ }^{(4)}$, a Qual implica o estabelecimento de um relacionamento guerreiro de dominação/obediência consigo próprio, sobre uma parte de si mesmo $^{(5)}$. Essa busca pelo domínio sobre si envolve empenho pessoal e implica em relação de luta (agonística) constante consigo próprio. No caso da relação conjugal compreendida como um todo 
Que integra amor, desejo, prazer e fidelidade, a luta do homem é estabelecida com seus possíveis desejos e impulsos, de tal forma Que os adversários a enfrentar fazem parte dele próprio.

Nessa maneira de viver em casal, as relações entre homem e mulher são mais igualitárias, com expectativas iguais para ambos em termos de amor, desejo, prazer e fidelidade. Ambos compartilham um projeto comum de vida, com a mesma participação/envolvimento na vida sexual, no delineamento de objetivos e na administração da vida cotidiana, mesmo Quando a mulher não exerce atividade remunerada fora do lar. A tomada de decisões cabe aos dois tendo o relacionamento e a família como referências principais.

Nesse caso, o domínio de si buscado na luta consigo próprio não é uma prática do homem voltado exclusivamente para si mesmo. Ao contrário, o trabalho realizado sobre si demanda a participação do outro e inclui também o convívio no casal e as demais relações sociais, revelando uma interseção entre o 'privado, interno, pessoal, íntimo' e o 'público, impessoal, externo, social'.

O relacionamento com o outro é constante na temática do cuidado de si, de tal maneira Que, sem o outro, nenhum autorelacionamento pode ocorrer satisfatoriamente ${ }^{(5)}$. A relação intersubjetiva é necessária à relação consigo mesmo, e essa inseparabilidade implica Que o homem cuida de si na relação consigo e com os outros.

$\mathrm{Na}$ construção cotidiana do viver em casal, os vínculos entre 'amor, desejo, prazer e fidelidade' podem também receber uma interpretação relativa, com dois desdobramentos possíveis. O primeiro indica uma cisão Que une amor, desejo e prazer, mas os separa da fidelidade. Aqui, apesar da satisfação com a vida conjugal, o homem mantém relações sexuais extraconjugais esporádicas por diferentes motivos.

Nessa cisão, fica aparente a separação entre o viver em casal, representativo de um mundo onde os afetos têm primazia e Que deve ser protegido, e um outro lado da vida, Que se passa à vista dos demais. Nesse outro lado, ele procura cumprir um referente de homem socialmente difundido, Que enfatiza a prontidão sexual e a heterossexualidade como características de um homem de verdade Que podem ser Questionadas e devem ser continuamente reafirmadas. Essa duplicidade não parece comprometer a imagem Que o homem tem de si e nem interferir na constituição de si como homem de verdade. Para tanto, é imperativo que o mundo dos afetos não tome conhecimento do outro.

As relações entre homem e mulher são menos igualitárias nessa maneira de viver em casal. Enquanto o homem considera compreensíveis, perdoáveis e até naturais suas possíveis traições e infidelidades, acredita Que o amor, desejo e prazer existentes na relação de casal bastem à mulher também em razão da natureza dela, diferente da sua especialmente em termos sexuais. Sua expectativa é Que a mulher compreenda e perdoe suas traições caso as 'descubra', embora a possível infidelidade da mulher seja inaceitável e imperdoável.

A norma da fidelidade no casal é reinterpretada e, ao vinculá-la com os sentimentos, o homem não reconhece como infidelidade os relacionamentos ocasionais e 'puramente físicos'. Aparentemente, isso não traz prejuízos à busca por um ideal de homem, e isso porque permite o cumprimento de um mandato essencial para tanto: casar com uma mulher Que ele escolha, constituir família, assumindo suas responsabilidades para com ela em todos os aspectos, características associadas à vida adulta. Ao mesmo tempo, Ihe possibilita manter um espaço de inconseqüência e irresponsabilidade na vida, manifestadas no sexo sem compromisso das relações ocasionais.

O domínio de si (enkrateia) é buscado não na fidelidade estrita à mulher e à família dentro do casamento, mas no controle de infidelidades e traições, cuidando para Que não ameacem a família e o relacionamento de casal. Viver assim parece requerer domínio sobre si, manifesto no comedimento, na estratégia e no segredo Que isso solicita. O princípio da escolha também é preservado, indicando a presença de um espaço de liberdade para o homem, Que não se vê como um 'escravo' de seus desejos e prazeres já Que os regula. Há, aqui, uma aproximação com a noção de sophrosune, pensada como superioridade da razão sobre o desejo ${ }^{(4)}$.

Entretanto, o fato de o homem considerar-se levado à infidelidade/traição por elementos exteriores e independentes de si próprio aponta na direção de uma certa passividade frente aos apelos Que o atraem, o Que o aproxima da intemperança - escolha deliberada de maus princípios ${ }^{(4)}$. Ser intemperante é encontrar-se em um estado de não resistência e em posição de fraqueza e submissão em relação à força dos prazeres; é ser incapaz dessa atitude de virilidade consigo Que permite ser mais forte do que si

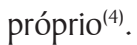

No segundo desdobramento, há uma cisão Que coloca os filhos em um campo diferente do ocupado pelo amor, desejo, prazer e fidelidade entre os parceiros. O homem revela insatisfação com todos os aspectos de sua vida conjugal, buscando fora dela a satisfação sexual e o prazer; nesse caso, o sentimento amoroso entre o casal é Questionado. Infidelidades e traições são comuns por parte do homem Que, fora do lar, assume um comportamento sexual predatório Que atesta sua heterossexualidade.

Se a insatisfação do homem com sua vida conjugal justifica as relações fora do lar, tê-las não contribui para Que se sinta mais satisfeito consigo próprio. Ao contrário, percebe-se em falha no atendimento de vários aspectos de um modelo de homem de verdade: como marido, como pai, como companheiro, como parceiro sexual da esposa, como chefe de família. Sente-se em erro ao trair a mulher, na Qual reconhece virtudes e Qualidades e, ao mesmo tempo, é incapaz de conter seus impulsos sexuais.

Embora a norma da fidelidade no casal seja considerada importante tanto para o homem como para a esposa, sentir-se incapaz de respeitá-la reflete sobre a imagem Que o homem tem de si e torna mais difícil o alcance daquele ideal. O homem parece não considerar esse estado de coisas como resultado de escolha sua, mas da 'situação'. Nesse caso, o homem não exerce controle sobre si e sobre seus desejos, entregando-se a eles sem exercer domínio sobre si próprio no campo sexual, o Que o aproxima da incontinência (akrasia). O incontinente se deixa levar, contra sua vontade e a despeito de seus princípios razoáveis, seja porQue não tem força para operá-los, seja porque não refletiu suficientemente sobre eles ${ }^{(4)}$.

Essa forma de viver sugere um prolongamento da fase de vida sexual intensa esperada e aceita para o jovem solteiro. Porém, a falta de responsabilidade e a intensidade da vida sexual em relações ocasionais ou duradouras com diferentes parceiras entra em conflito com a existência da esposa e da família, centrais no processo de 
tornar-se homem. Os elementos aQui considerados colocam a relação 'amor, desejo, prazer e fidelidade' como uma verdade no relacionamento conjugal. A maneira como o homem estabelece sua relação com essa verdade o constitui como sujeito e culmina com a elaboração de uma estética da existência, na eual o valor moral da maneira de viver depende de certos princípios formais gerais seguidos no uso dos prazeres e nos limites Que se observam nele.

\section{Uso de Preservativo}

No relacionamento de casal, o uso do preservativo pode ser intermitente, coincidindo com os intervalos Que a mulher faz no uso do anticoncepcional oral (AO); ou contínuo, motivado pela impossibilidade de a mulher utilizar AO. No Que se refere a relações extraconjugais, o uso do preservativo pelo homem em todas elas visa a evitar Que sejam denunciadas por gravidez ou por doenças, colocando em risco a família. Assim, ele mantém o mundo de fora afastado do mundo de casa.

Essa situação reforça a localização do homem entre dois mundos: o da família, de casa, dos afetos, onde assume uma imagem de homem compatível com o ideal, e o mundo de 'fora', das relações mais impessoais, onde procura preservar uma imagem Que enfatiza o caráter indomável da sexualidade masculina e a prontidão para o sexo. O trânsito entre esses dois mundos exige atenção permanente, bem como certa dose de escolha e comedimento no sentido de mantê-los ignorantes um do outro.

O estabelecimento de uma separação entre prazer e razão devido à existência de uma incompatibilidade natural entre eles, impede o homem de pensar naquilo Que vai fazer no momento de uma relação sexual. Fora de casa, o uso do preservativo solicita um exercício de racionalidade em um momento em Que a busca pelo prazer é premente. Essa premência, aliada à imprevisibilidade desses encontros sexuais e à possibilidade de perder a oportunidade de manter relação sexual, impede Que considere racionalmente a situação dificultando o uso do preservativo. A crença de Que o preservativo reduz o prazer sexual, interrompe a interação homem-mulher e impede o contato direto entre ambos também contribui para o não uso.

O homem usa alguns indicativos para justificar o uso irregular do preservativo nas relações extraconjugais, dentre os Quais a vida sexual anterior da parceira por ele avaliada como pobre em número de parceiros e de relações ${ }^{(6)}$. Neste caso, o relato de poucos parceiros sexuais, demonstrações de pouca experiência sexual e de timidez parecem ser utilizados pelo homem para dispensar o uso do preservativo.

Isso pode ocorrer também Quando a relação extraconjugal se prolonga e o principal argumento para abandonar o preservativo é a crença de Que ela não 'fica' com mais ninguém e, nisso, a intuição do homem é importante. Nessa situação é preciso considerar aQuilo Que, com base em Vieira et $\mathrm{al}^{(7)}$, denominamos fidelidade seriada Que considera uma parceira extraconjugal por vez, embora implieue a existência de muitas antecedendo e sucedendo a relação atual.

No Que se refere a sexo seguro, conhecer a companheira é apontado como um elemento importante. Entretanto, conhecer bem a pessoa' não indica intimidade e longo convívio entre os parceiros, mas um continuum Que se estende desde o 'conhecer a parceira desde a infância, por residirem no mesmo bairro ou estudarem juntos', até o máximo de intimidade e cumplicidade no convívio.
A confiança na parceira é central para o sexo seguro e forma uma díade ambivalente com a desconfiança Quando se refere à fidelidade dela. Confiar na parceira é uma aposta Que o homem faz na relação conjugal Que traz alguns riscos, pois ele só pode ter certeza de seu próprio comportamento. Um pacto de confiança e fidelidade mútuas deixa para ambos o compromisso de zelar pelo fortalecimento e pela manutenção da relação e da família.

Evocando a analítica do poder de Foucault, cabe a cada um dos parceiros exercer vigilância sobre si próprio - mais do Que vigiar o comportamento do outro - de maneira a atender as demandas desse pacto. A percepção do Que é ser homem exerce grande influência e o cuidado de si, compreendido como um trabalho continuamente exercido pelo homem sobre si próprio, conduzindose de maneira compatível com um código de conduta Que tenha para si, assume posição central na prevenção de DST/AIDS e no sexo seguro.

\section{O Poder em Circulação nas Relações de Casal}

Os elementos relativos à vida afetivo-sexual permitem perceber variações na dinâmica de circulação do poder nas relações de casal e, em todas, a idéia de fidelidade, desejo, prazer sexual e família ocupam posição central, exercendo forte influência sobre o relacionamento conjugal e sendo por ele influenciados. O relacionamento de casal e o convívio com a esposa e com a família embasam a avaliação Que o homem faz de si mesmo e para a avaliação Que os outros fazem dele como homem.

A primeira variação na dinâmica das relações de poder - relações equilibradas de poder no casal, com pacto de fidelidade entre marido e mulher e satisfação do homem com a vida sexual e com o relacionamento conjugal como um todo(3) - sugere uma dinâmica Que coloca homem e mulher juntos, ocupando posições iguais no centro das relações de poder. O poder circula de um para o outro e os envolve, movimentando equilibradamente sua teia, sem prevalência duradoura de um em detrimento do outro. Utilizando a metáfora da balança, pode-se imaginar o poder movimentandose para um lado e para outro, sem Que as assimetrias se acentuem ou se prolonguem. As relações de gênero são mais igualitárias, sem as polaridades dos papéis e das características tradicionalmente atribuídas a homem e mulher.

A segunda variação - relações assimétricas de poder nas Quais o homem ocupa posição de destaque, está satisfeito com a vida sexual do casal e com o relacionamento conjugal como um todo, considera normal Que o homem traia e que a mulher seja fiel(1) aponta uma dinâmica de relações de poder onde o homem é a figura principal. Ele domina grande parte do viver em casal, deixando para ela as atividades tradicionalmente relacionadas à figura feminina, as Quais acompanha ajudando eventualmente.

$\mathrm{Na}$ terceira variação - relações de poder desordenadas, conflituosas, nas Quais o homem demonstra insatisfação com a vida sexual do casal e com o relacionamento conjugal como um todo, envolve-se em infidelidades e traições, embora espere que a mulher Ihe seja fiel(3) - o casal compartilha a família, os filhos e a casa, assumindo suas responsabilidades para com eles. Os filhos são o elo Que mantém o casal. A falta de desejo/prazer sexual da esposa e a divergência de prioridades são os principais motivos da situação. No campo sexual, apesar das infidelidades e traições o homem acredita Que a mulher não tomará atitude semelhante por 
não gostar de sexo. Apesar da insatisfação com a vida conjugal e de pensar em separar-se, o homem mantém as relações extraconjugais em segredo, para Que a família não seja ameaçada e ele não corra o risco de perder os filhos. A satisfação sexual buscada fora de casa tem efeitos negativos sobre a busca pelo reconhecimento público como homem. O comportamento heterossexual predatório, considerado inerente ao homem, entra em conflito com elementos essenciais a uma vida de homem adulto e responsável: esposa, família e filhos.

Cada uma das variações descritas tem implicações no trabalho de educação em saúde com vistas à promoção da saúde e focalizado nas DST/AIDS. Assim sendo, na primeira variação, a possibilidade de DST/AIDS é remotamente considerada e está na maioria das vezes relacionada com formas de contaminação concebíveis em um relacionamento dessa natureza: transfusão sangüínea e acidentes com material contaminado.

O pacto de fidelidade, assumido como compromisso consigo próprio e com a mulher, contribui para Que o homem considere remota a hipótese de contaminação sexual. Entretanto, mesmo remota, a possibilidade de contrair DST/AIDS provoca certa insegurança no homem, Que se sente dependente do comportamento da parceira nessa Questão. Procura superar esta insegurança confiando nela e estabelecendo um bom nível de diálogo Que permita o fortalecimento da relação e a troca de informações.

Mesmo declarando-se fiel à esposa, o homem não exclui a possibilidade de um relacionamento extraconjugal, o que está ligado ao caráter incerto do futuro. As DST/AIDS são motivo de preocupação Quando pensa nos/as filhos/as, os/as Quais iniciarão suas vidas sexuais ainda jovens e em tempos de aids, o Que os torna vulneráveis. Nesse ponto, a importância do pai na vida dos/as filhos/ as é evocada e a crença na força educativa do seu exemplo pessoal o estimula a vigiar seu comportamento. Além da educação pelo exemplo, o diálogo é valorizado desde cedo para fortalecer os laços afetivos e estabelecer uma relação de confiança Que permita abordar Questões relativas à sexualidade, dentre as Quais as DST/AIDS.

Assim, a prescrição do uso do preservativo associado à fidelidade tem pouca ressonância entre homens Que mantêm relacionamentos conjugais semelhantes ao aQui descrito, posto Que consideram o preservativo desnecessário em virtude do pacto de fidelidade estabelecido com a esposa. Entretanto, se a proposição do preservativo na relação conjugal é incompatível com esse pacto e com a relação de confiança mútua existente no casal, o caráter potencialmente instável da fidelidade abre caminho para a discussão sobre o uso do preservativo na ocorrência eventual de relacionamentos extraconjugais. Neste particular, é importante tomar as experiências do homem como ponto de partida para a discussão, especialmente se ela se der em grupo, onde as vivências e as opiniões de cada um têm valor. O profissional participa do grupo, compartilhando suas vivências e saberes em um relacionamento no Qual as posições de poder têm maior simetria. Nestas circunstâncias, o caráter prescritivo, impositivo e definitivo geralmente relacionado ao saber científico é amenizado e/ou eliminado, possibilitando o diálogo.

$\mathrm{O}$ valor e o significado atribuídos à família nos permitem pensar no homem e na mulher como partes de um mesmo pacote - a família - motivo e objetivo de suas ações. Ambas as partes perdem muito Quando considerados fora desse contexto. Esta compreensão coloca a família como elemento-chave para a promoção da saúde.
Na segunda variação observada na dinâmica das relações de poder, as implicações para o trabalho de educação em saúde guardam semelhanças com a situação anterior, especialmente no Que se refere à figura do homem-pai e à educação dos filhos. Dentre as diferenças, desponta a separação entre o mundo de 'dentro' e o de 'fora', associada ao duplo padrão sexual para o homem e para a mulher e à posição ocupada pela fidelidade. A separação de espaços faz com Que o homem deixe transparecer duas faces aparentemente antagônicas de si próprio: uma revelada na família e outra fora dela e, no campo sexual, o Que as diferencia é o afeto e/ou compromisso Que marcam as relações e Que caracterizam a fidelidade. Estabelecida essa diferenciação, o homem adota condutas diferentes para os dois mundos.

Mesmo combinando o viver em casal com infidelidades e traições, o homem atribui grande importância à família, em relação à Qual assume um papel protetor nos dois mundos. Para evitar ameaças, as traições são cercadas de cuidados, Que incluem desde a seleção da parceira, até o uso do preservativo em todas as relações extraconjugais e à circunscrição delas a um curto período de duração (geralmente um ou dois encontros).

O papel protetor do homem é ambíguo, especialmente no mundo de 'fora' porQue, regulando o trânsito da família por ele, o homem protege a si próprio, evitando Que infidelidades e traições venham à tona. Assim, protege a família de ameaças externas a ela, reduzindo as possibilidades de que sua própria vida nesse mundo de fora seja 'descoberta'.

Contrariamente ao encontrado nas duas primeiras, na terceira variação das relações de poder a família é motivo de conflito para o homem, que a reconhece como requisito essencial para tornarse homem de verdade e, ao mesmo tempo, se sente incapaz de atender a todas as demandas Que ela exerce sobre ele.

Para um trabalho de educação em saúde, a figura do homempai surge como possibilidade de abordagem, justamente pela grande importância Que os filhos têm no processo de tornar-se homem e da preocupação do homem com a possível influência do seu exemplo (Que, segundo ele, não é bom) na educação deles. Entretanto, mesmo com a referência aos filhos, é possível perceber que a preocupação principal do homem é consigo próprio.

No Que se refere às DST/AIDS, a prevenção visando a saúde da mulher não tem ressonância, isso porQue o homem mantém um distanciamento afetivo da esposa (aliado a um distanciamento sexual) e das 'outras'. A busca pelo prazer sexual é o elemento central e, embora valorize também o prazer sentido pela mulher em uma relação sexual, ele o faz pelo seu próprio prazer, Que é maior Quando a relação é prazerosa para a mulher. Esse aspecto deve ser considerado nas iniciativas de educação em saúde, de maneira a possibilitar a discussão sobre autoproteção, práticas de sexo mais seguro para a prevenção de DST/AIDS, juntamente com as discussões de Questões de fundo, como as relacionadas ao gênero, aos estereótipos de masculinidade e feminilidade, ao processo de tornar-se homem, à sexualidade, à paternidade, dentre outros tantos.

\section{CONSIDERAÇÕES FINAIS}

As considerações até aQui tecidas evidenciam a insuficiência de iniciativas de educação em saúde baseadas na recomendação de cuidados a serem tomados no campo sexual para prevenção de 
DST/AIDS justamente por fazerem um recorte no viver das pessoas Que destaca e isola a sexualidade. Essas recomendações são importantes e necessárias, especialmente Quando utilizadas em campanhas de prevenção, nas Quais os Que as idealizam e aQueles a Quem se destinam fazem parte de uma massa anônima e considerada uniforme. Discutir o viver em casal, a educação dos/ as filhos/as, a concepção de homem sob a perspectiva de gênero contribui para Que o caráter de construção sociocultural dessas Questões seja percebido. O diálogo é ferramenta indispensável para Que a experiência de vida do homem fundamente e oriente a iniciativa de educação em saúde.

O foco de atenção dos homens Que vivem a fase de 'aproveitar a vida' (intensa vida sexual e valorização do grupo de amigos) está centrado em si próprios, o Que pode torná-los menos sensíveis a recomendações de práticas sexuais mais seguras para proteção da saúde da parceira. Nesses casos, a ênfase na autoproteção pode ser mais efetiva, especialmente Quando discutida com outros homens de diferentes idades. O diálogo e a troca de experiências de vida permitem aprender com os outros, considerando a própria experiência de vida a partir de diferentes pontos de vista, aumentando as possibilidades de escolher e decidir.

A noção de cuidado de si como um exercício de conhecimento de si continuamente desenvolvido ao longo do viver pode ajudar o homem a encontrar a si próprio no meio das demandas muitas vezes contraditórias Que o pressionam. Conhecer a si mesmo, reconhecendo Quais são os valores fundamentais em sua vida, o Que é ser homem para si, Quais das demandas impostas adota para si, lhe possibilitará um certo grau de liberdade frente aos outros, definindo um modo de vida congruente consigo mesmo.

Isso reforça a necessidade de promoção da saúde pelo desenvolvimento de iniciativas de educação em saúde Que tomem a vivência das pessoas como matéria-prima, evitando prescrições de conduta baseadas nas verdades científicas e naquilo que é comumente aceito como verdadeiro por todos (por exemplo, as verdades estabelecidas sobre o que é ser homem e sua vida afetivosexual) e fomentando um movimento capilar 'de baixo para cima' Que facilite o encontro entre o vivido pelas pessoas e as recomendações cientificas.

Além disso, outros aspectos merecem ser abordados no desenvolvimento de iniciativas de educação em saúde visando à promoção da saúde e não apenas à prevenção de DST/AIDS. Dentre esses, incluem-se as relações de gênero, a posição/situação/ condição de mulheres e homens no mundo contemporâneo, os direitos das mulheres como direitos humanos, as relações conjugais e o poder Que nelas circula, as estereotipias, os direitos reprodutivos e sexuais. Todos merecem ser discutidos com base na vivência e oferecerão subsídios para a orientação/educação dos/as filhos/as, valorizando a figura do homem-pai na família.

\section{REFERÊNCIAS}

I. Foucault M. Microfísica do poder. Rio de Janeiro: Graal; 1995b.

2. Foucault M. Em defesa da sociedade: curso no Còllege de France (1975-1976). São Paulo: Martins Fontes; 2000.

3. Madureira VSF. A visão masculina nas relações de poder no casal heterossexual como subsídio para a educação em saúde na prevenção de DST/aids [tese]. Florianópolis (SC): Programa de Pós-Graduação em Enfermagem; Universidade Federal de Santa Catarina; 2005.

4. Foucault M. A historia da sexualidade: o uso dos prazeres. Rio de Janeiro: Graal; 1998.
5. Ortega F. Amizade e estética da existência em Foucault. Rio de Janeiro: Graal; 1999.

6. Almeida MV. Senhores de si: uma interpretação antropológica da masculinidade. $2^{\mathrm{a}}$ ed. Lisboa: Fim de Século; 2000.

7. Vieira EM, Fernandes MEL, Díaz J, Kalckmann S, Pluciennick AMA. Anticoncepção em tempos de aids. In: Galvão L, Díaz I, organizadores. Saúde sexual e reprodutiva no Brasil: dilemas e desafios. São Paulo: Hucitec; 1999. 